\title{
Restriction fragment patterns and emm types of group $\mathrm{G}$ streptococci
}

Group G streptococci (GGS) are aetiological agents of exudative pharyngitis, pyoderma, invasive infections and post-streptococcal sequelae (Zaoutis et al., 2004; Steer et al., 2009). Like group A streptococci (GAS), GGS also express M protein and other virulence factors such as fibronectin binding proteins, IgG binding protein, streptokinase, streptolysin $\mathrm{O}$, streptolysin S, streptococcal pyrogenic exotoxins, C5a peptidase and NADase (Chhatwal \& Talay, 2000), and have $\mathrm{emm}$ genes that encode $\mathrm{M}$ protein similar to that of GAS. More than 60 sequence types have been described for group C streptococci and GGS (Streptococcus pyogenes emm sequence database: BLAST emm - Centers for Disease Control and Prevention, 2008 http://www.cdc.gov/ncidod/biotech/strep/ strepblast.htm). Restriction profiles of $\mathrm{emm}$ amplicons of GAS have been used in the past to detect groups of isolates with identical emm types (Beall et al., 1998; Mylvaganam et al., 2009). We wished to study the correlation between the RFLP profiles of emm amplicons of GGS strains obtained using single (DdeI) and double digests (HincII and HaeIII) with the emm sequence types, and the possibility of using RFLP to type GGS strains, in a similar manner to the identification of emm types of GAS.

A total of 18 strains of GGS isolated from throat swabs (12), skin swabs (3), blood (2) and fluid (1) were included in the study. The study was approved by the institutional ethical committee. DNA extraction and amplification of the $\mathrm{emm}$ gene was carried out using standard techniques, and the emm types of the isolates was determined (Streptococcus pyogenes emm sequence database: protocol for emm typing - Centers for Disease Control and Prevention, 2008 - http:// www.cdc.gov/ncidod/biotech/strep/ protocol_emm-type.htm). emm amplicons were digested with restriction enzyme DdeI, and double digested with HincII and HaeIII. Restriction digestion with DdeI was carried out using $5 \mu \mathrm{emm}$ amplicon DNA, $0.5 \mu \mathrm{l}$ DdeI and $0.5 \mu \mathrm{l} 1 \times \mathrm{NE}$ buffer 3 (New England BioLabs), which was incubated at $37{ }^{\circ} \mathrm{C}$ in a water bath for $40 \mathrm{~min}$. For double digestion, $4 \mu \mathrm{lemm}$ amplicon DNA was digested with $0.4 \mu \mathrm{l}$ each of HincII and HaeIII in $0.5 \mu \mathrm{l} 1 \times \mathrm{NE}$ buffer 2 and $0.1 \mu \mathrm{l} 100 \times \mathrm{BSA}$ (New England BioLabs), at $37^{\circ} \mathrm{C}$ for $40 \mathrm{~min}$. The fragments were resolved using $2.5 \%$ agarose (Sigma Aldrich) with a $50 \mathrm{bp}$ molecular mass marker.

Dendrogram analysis of RFLP fragments was carried out using DNA Fingerprinting II Informatix software version 3.0 (BioRad), using the UPGMA algorithm and Dice similarity coefficients. Simpson's diversity index was applied to compare the discriminatory ability of the RFLP profiles obtained by single and double digestion of emm amplicons (Simpson, 1949).

A total of 8 different emm types were detected among 18 GGS strains [stG6792.3 (8), stG866.0 (3), stG1750.0 (2), stG652.0 (1), stG643.1 (1), stG653.0 (1), stG2574.0 (1), stC2sk.0 (1)] resulting in a strain diversity of $44.4 \%$. Dendrogram analysis of the 18 GGS strains using the single digest profiles showed 18 different clusters, giving a $100 \%$ strain diversity (Fig. 1). Simpson's diversity index for single digest profiles was zero showing their poor discriminatory ability.
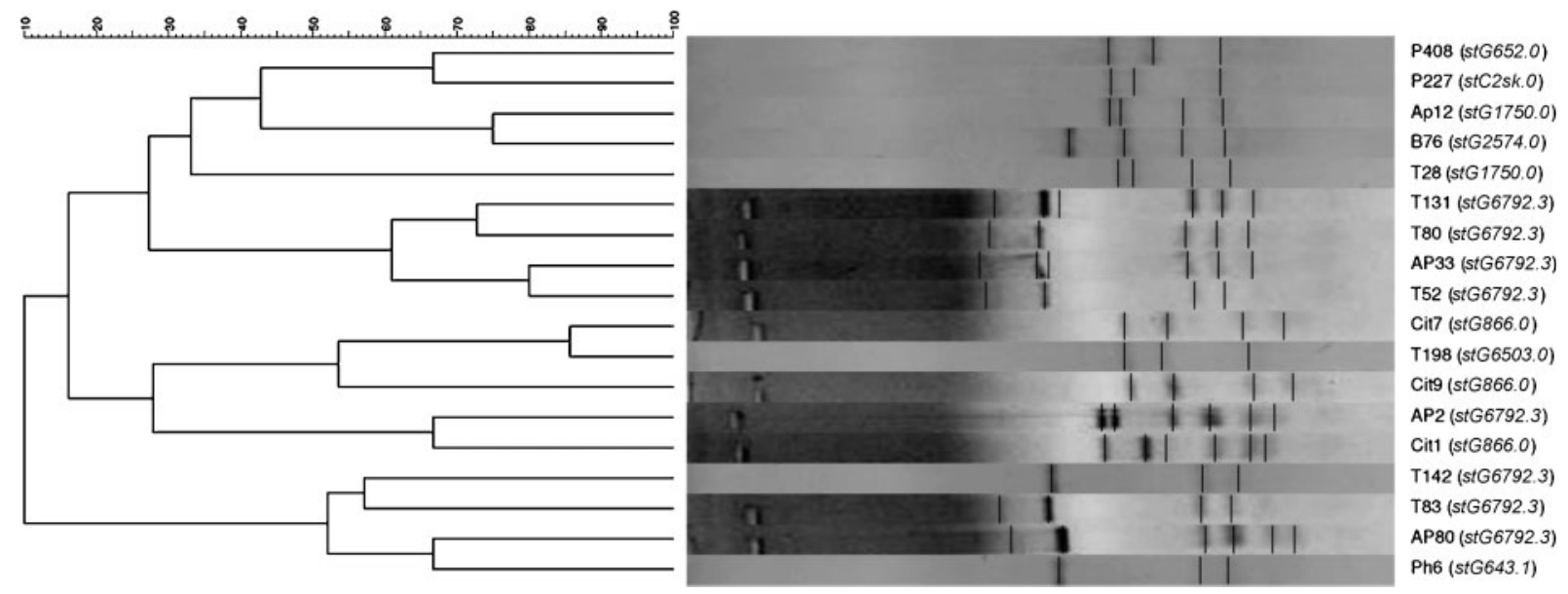

Fig. 1. Dendrogram of RFLP patterns of Ddel digests. The dendrogram was constructed with Fingerprinting II Informatix software version 3.0 with $0 \%$ optimization and $0.87 \%$ positional tolerance, by using the UPGMA algorithm and Dice similarity coefficients. Strain numbers and emm sequence types are indicated on the right. 


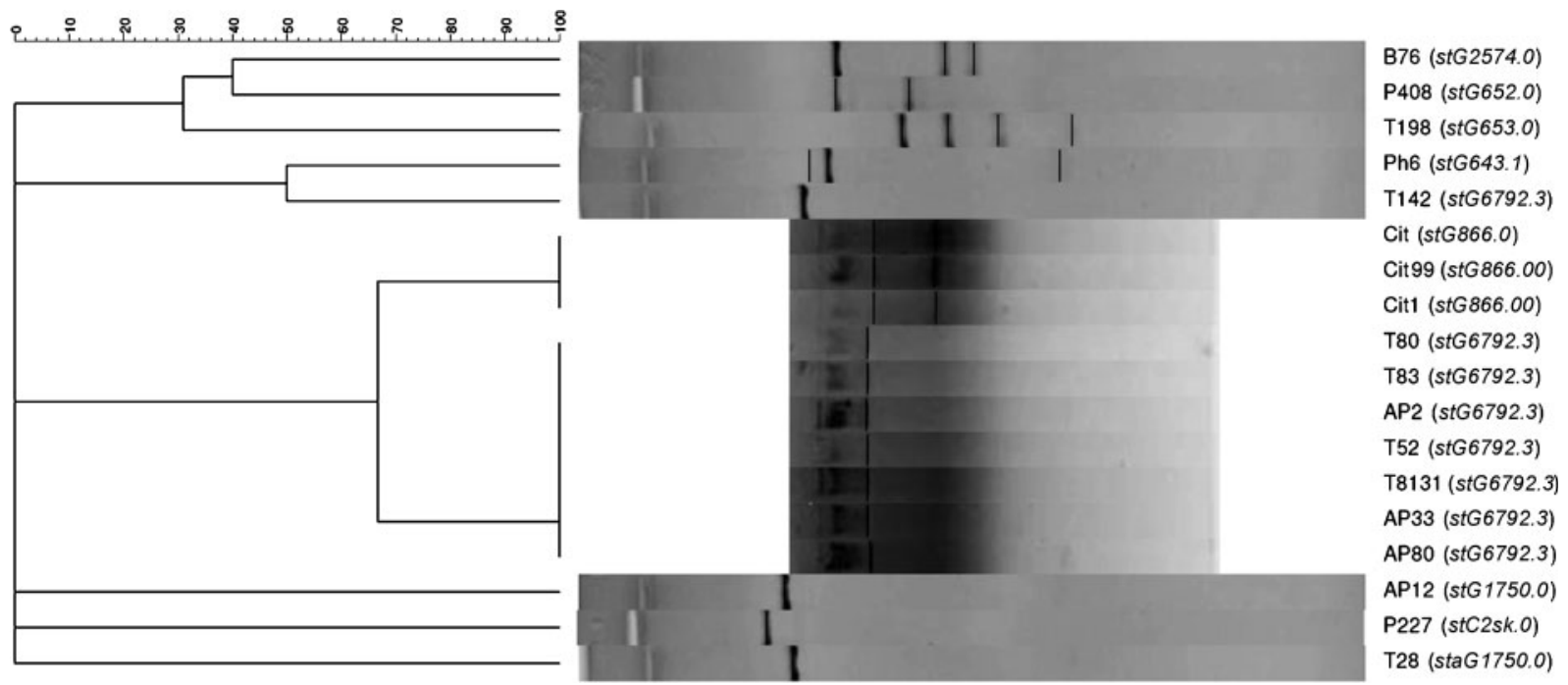

Fig. 2. Dendrogram of RFLP patterns of Hincll + Haelll digests. The dendrogram was constructed with Fingerprinting II Informatix software version 3.0 with $0 \%$ optimization and $0.87 \%$ positional tolerance, by using the UPGMA algorithm and Dice similarity coefficients. Strain numbers and emm sequence types are indicated on the right.

Dendrogram analysis of strains using double digest profiles showed 10 restriction profiles at a $100 \%$ similarity coefficient, with a strain diversity of $55.6 \%$ (Fig. 2). Seven among the eight strains with emm type stG6792.3 belonged to a single cluster and exhibited identical profiles. Similarly, three strains belonging to the type emm866.0 showed $100 \%$ similarity in their restriction profiles. However, two strains with emm type stG1750.0 showed dissimilar restriction profiles. Simpson's index of diversity for double digestion was 0.7 .

Single digest profiles were less discriminatory, since none of the strains with a similar emm type (stG6792.3, stG866.0 and stG1750.0) showed similar RFLP profiles. These findings appeared to be similar to those found for GAS (Streptococcus pyogenes emm sequence database: protocol for emm typing Centers for Disease Control and Prevention, 2008 - http://www.cdc.gov/ ncidod/biotech/strep/protocol_emm-type. htm). Double digest profiles were more discriminatory, since strains belonging to the same emm type [stG6792.3 (7/8), stG866.0 (3/3)] belonged to the same cluster with $100 \%$ similarity in their restriction profiles. Though this study included only a small number of strains, preliminary results do show that RFLP profiles of double digests (HincII and HaeIII) of emm amplicons correlate with the emm sequence type, while single digests with DdeI do not discriminate between emm types. Hence, restriction profiling using HincII and HaeIII may be used to detect GGS with identical emm types and may serve as a less expensive method of molecular typing the strains.

\section{Acknowledgements}

We thank the Department of Biotechnology (DBT), New Delhi, India, for the financial support, and Central Institute of Brackish Water and Aquaculture (CIBA), Chennai, India, for their assistance in dendrogram analysis.

\section{Malathy Balaraman and Thangam Menon}

Department of Microbiology, Dr A. L. Mudaliar Post Graduate Institute of Basic Medical Sciences, University of Madras, Taramani Campus, Chennai 113, India

Correspondence: Thangam Menon (thangam56@gmail.com)
Beall, B., Facklam, R. R., Elliot, J. A., Franklin, A. R., Hoenes, T., Jackson, D., Laclaire, L., Thompson, T. \& Viswanathan, R. (1998). Streptococcal emm types associated with Tagglutination types and the use of conserved emm gene restriction fragment patterns for subtyping group A streptococci. J Med Microbiol 47, 893-898.

Chhatwal, G. S. \& Talay, S. R. (2000).

Pathogenicity factors in group $\mathrm{C}$ and $\mathrm{G}$ streptococci. In The Gram-Positive Pathogens, pp. 163-176. Edited by V. A. Fiscetti, R. P. Novick, J. J. Ferretti, D. A. Portnoy \& J. I. Rood. Washington, DC: American Society for Microbiology.

Mylvaganam, H., Bruun, T., Vindenes, H. A., Langeland, N. \& Skrede, S. (2009). Molecular epidemiological investigation of an outbreak of invasive $\beta$-haemolytic streptococcal infection in western Norway. Clin Microbiol Infect 15, 245-252.

Simpson, E. H. (1949). Measurement of diversity. Nature 163, 688.

Steer, A. C., Jenney, A. W., Kado, J., Good, M. F., Batzloff, M., Magor, G., Ritika, R., Mulholland, K. E. \& Carapetis, J. R. (2009). Prospective surveillance of streptococcal sore throat in a tropical country. Pediatr Infect Dis J 28, 477-482.

Zaoutis, T., Attia, M., Gross, R. \& Klein, J. (2004). The role of group $C$ and group $G$ streptococci in acute pharyngitis in children. Clin Microbiol Infect 10, 37-40. 